\title{
Analysis of Mobile Electronic Commerce Development Present Situation and Influence Factors
}

\author{
Zhu Tao, Qin Peng and Lu Zhao \\ Nanchang Key Laboratory of material and structure detection Jiangxi University of Technology
}

Keywords: Mobile e-commerce; Current development; Influencing factors

\begin{abstract}
As the most dynamic new favorite of the information age, mobile e-commerce is the third form in the development of e-commerce and it has achieved the second leap of e-commerce. Compared with traditional e-commerce, mobile e-commerce has three distinctive characteristics: provide $3 \mathrm{~A}$ services, that is, obtain information and services of the entire network at any time and any place. With the development of the increasingly progressing mobile communication technology, there is a trend that mobile e-commerce is gradually exceeding the development of traditional e-commerce. This paper mainly takes China's current mobile e-commerce as the research object to analyze prospect for the development of China's mobile e-commerce and factors restricting the development of China's mobile e-commerce, and the proposes countermeasures and suggestions to improve and promote China's mobile electronics market.
\end{abstract}

\section{Introduction}

With the rapid development of China's wireless network as well as $3 \mathrm{G}$ and $4 \mathrm{G}$ network, the threshold for people to have access to the Internet and use information is lowered. Mobile e-commerce services begin to flourish with a trend of exceeding traditional e-commerce. Mobile e-commerce does not only promote economic development, but also creates more opportunities to individuals. Currently, more and more merchants begin to settle in each major e-commerce platform, injecting fresh and surging blood to this industry. M-commerce refers to B2B or B2C e-commerce by combining mobile communication equipment, such as mobile phones, PDA, handheld computers and notebooks with wireless network technologies. Currently, there are still some problems in China's mobile e-commerce, such as the security issue, shortage of resources through wireless channels, quality problem and problems in the design of mobile terminals, etc. To promote the rapid development of mobile e-commerce, it is necessary to adopt measures like improve terminal design, perfect payment and security certification system, expand range of application and enrich contents of services, etc.

\section{Current Situation of China's Mobile E-Commerce and Its Main Influencing Factors}

Current Situation of China's Mobile E-Comme rce. Mobile Phone Users are Scaled Up: According to data of the "CNNIC $33^{\text {rd }}$ Investigation Statistical Report of the Development of the Internet in China", up until the end of December 2013, there were 618 million Internet users in China with the popularity of the Internet up to $45.8 \%$, a $3.7 \%$ increase compared with that at the end of 2012 with 53.58 new Internet users. Mobile Internet users in China grew ever faster, reaching 500 million in 2013, an increase of 8.9 million compared with that at the end of 2012, exceeding the overall growth of the Internet users. 


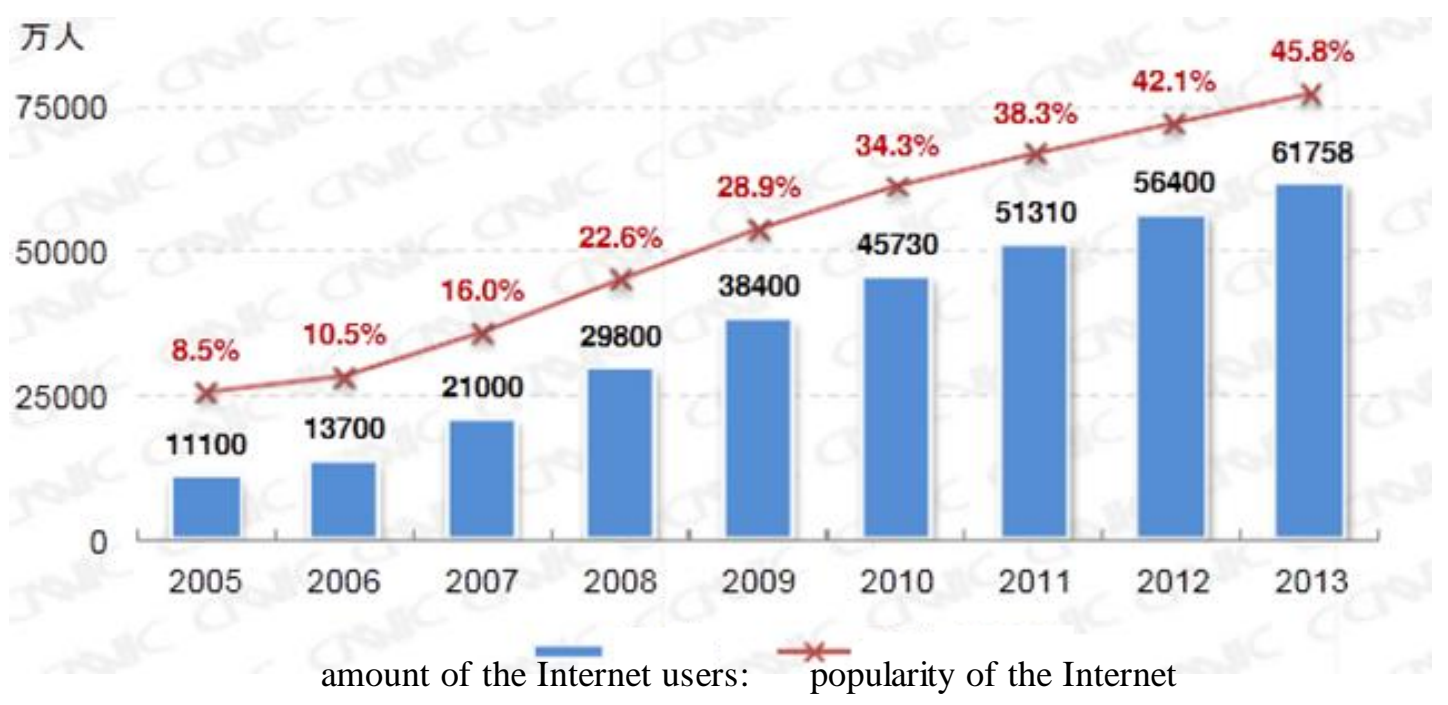

Fig. 1 Scale of Chinese Internet Users and Popularity of the Internet in China

ten thousand:

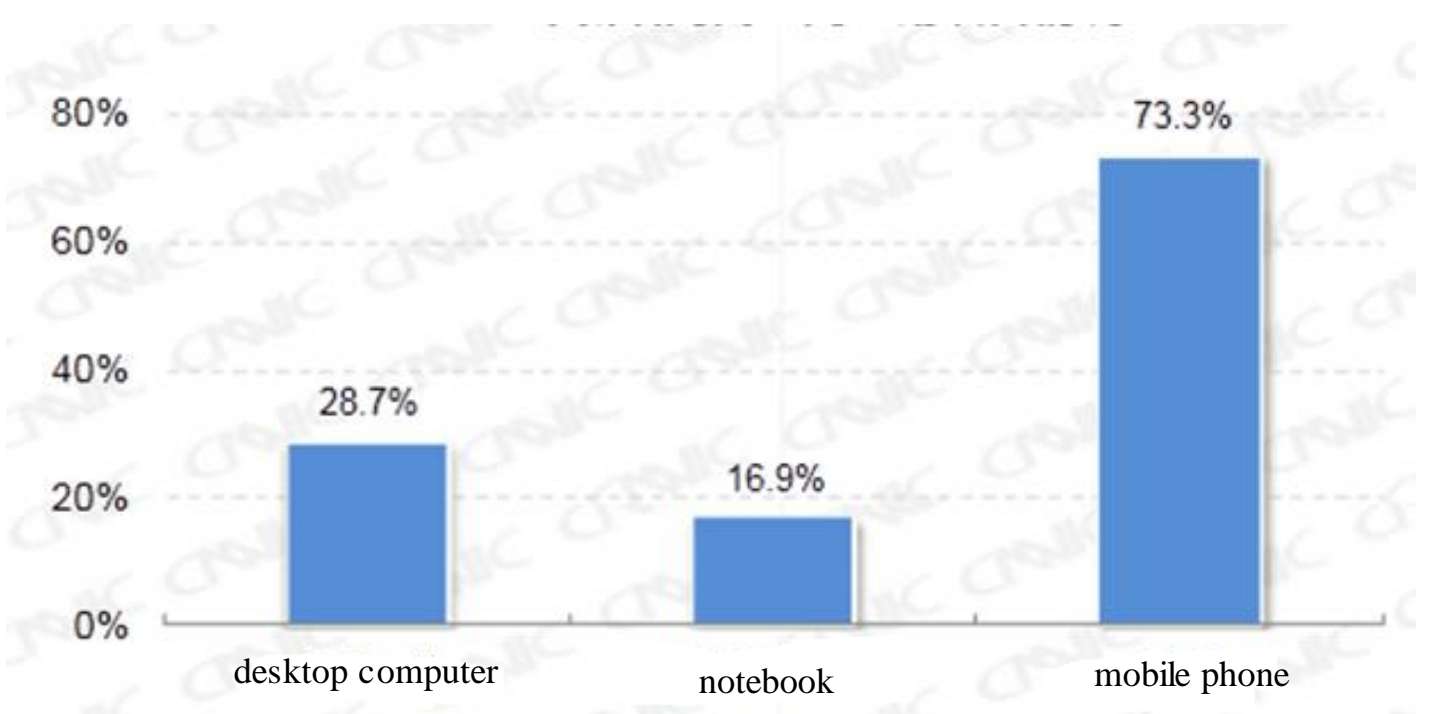

Fig. 2 New Internet Users' Equipment of Surfing the Internet in 2013

E-Commerce Market is Gradually Maturing:

The e-commerce market in China has just been opened for about ten years, but it was during this period that e-commerce develops fast in China. During these ten years, more and more people accept this new consumption mode of online shopping with an increasing amount of e-commerce enterprises going deep into people's lives.

Increasing Popularity of Intelligent Mobile Devices and Improved Performance:

In recent years, there is an increasing number of people using smartphones and mobile equipment just like rolling the snowball, demonstrating an unmanageable trend, and the explosive increase of intelligent mobile equipment is changing people's lifestyles and consumption habits. It can be found that there are more and more people using the mobile phone to play games, chat on microblog and WeChat, and watch TV series. This is definitely the best way of interpersonal 
communication, but it has already become a perfect condition for the development of mobile e-commerce in China.

With the rapid popularization of intelligent terminals in the field of handheld device, consumers have diversified and personalized choices for intelligent terminals, especially, the choice of intelligent terminals' contents has already become a key factor concerned by consumers.

Constant Innovation in the Application of Mobile E-Commerce:

In today's society, mobile e-commerce is familiar to and used by more and more people. The popularization of terminals and innovation of the application of the Internet are important factors to another round of growth for mobile e-commerce. With the gradual increase of smartphones' market share and the constant enhancement of smartphones' performance, there is a surge of innovation in mobile online application. Meanwhile, price of mobile phones is constantly reducing, reducing the threshold for the use of mobile intelligent terminals so as to promote ordinary mobile phone users become mobile Internet users. Currently, customers have basically developed the habit of surfing the Internet through mobile intelligent terminals, laying a good foundation for the further development of mobile e-commerce.

Analysis of Main Influencing Factors. Compared with traditional e-commerce, mobile e-commerce can provide users with necessary information, application and services at any moment and anywhere, meanwhile satisfying users' and merchants' demand for security, social relationship and self-realization. Thus, it has obvious advantages. However, the system for the development of mobile e-commerce is not perfect with a lot of problems such as mobile network security, mobile payment mechanism, technical support of mobile e-commerce and legal problem of mobile e-commerce, etc. All these produce restriction to the development of mobile e-commerce, and main factors influencing mobile e-commerce include:

Security of Mobile Network:

Secure operating environment is the foundation of mobile e-commerce development, the key is whether it can be accepted by people, and also only use safe operating techniques can be recognized by many consumers really. However, due to the development of mobile e-commerce start-up, safe and relatively simple technical means. As current mobile payment behavior is based on mobile terminals that are bound by bank card, credit card and merchant, or on cell phone SIM card and POS machines at close range. If mobile or password cracking are lost, information replication, virus infections and other security issues are likely to cause major damage to mobile payments. Mobile security issues will gradually directly affect the country's long-term development of mobile e-commerce.

Mobile Payment Mechanism:

With the $3 \mathrm{G}$ network construction and application of Internet of things technology, universal intelligent terminals and other infrastructure continues to improve, mobile payment has become a mainstream development direction of electronic payment methods and focus of market competition, but also payment mechanism problem. In paid company aspects, although has basic solution has traditional of paid security problem, and paid costs problem,, but in recent years poured into many of paid company, makes part paid company of profit status fell, some paid company even basic of survival are problematic; in Bank aspects, rapid development of Internet completely Subversion has Bank on holding card user of traditional service thinking, makes of became more electronic of, and convenient of and personalized. In addition, each bank branch to deposit or other competitive resources near "no line" to ease restrictions on access, lower access prices, bad electrical contractor and third party payment companies have a considerable deal but overdrawn the vitality of these electronic channels, especially security without reliable protection.

Technical Support of Mobile E-Commerce:

Payment system of mobile e-commerce has always been the most concern to people because this link is directly related to the whereabouts of fund. Once there is problem in the electronic payment link, it will be likely cause loss of both life and wealth. In addition, there are still a lot of 
security and technical loopholes in the mobile e-commerce payment system, so it is unable to give people enough credit.

Legal Problem with Mobile E-Commerce:

China has already formulated a series of laws and regulations, such as E-Commerce Signature Law, Online Information and Contents Services Management and Interim Measures of Online Banking Business Management to effectively regulate the development of e-commerce. However, there is still no law or regulation aiming at mobile e-commerce, and it is a blank area to solve disputes of e-commerce transactions through legal means. The government should strengthen the construction of e-commerce business laws and regulations, formulate relevant policies beneficial for the development of e-commerce, establish effective management mechanism for the development of mobile e-commerce, strengthen market supervision under the environment of the Internet, regulate online transaction behaviors and guarantee the security of users' information and funds.

\section{Countermeasures and Suggestions}

As mobile e-commerce is still a new field in China, so there is few content in China's e-commerce laws and regulations that have already been promulgated involving mobile e-commerce, and relevant local regulations are more or less limited, causing very loose supervision of the mobile e-commerce market. Therefore, China's legislative department should try to formulate Mobile E-Commerce Law which is suitable for China's situation so as to make the development of mobile e-commerce in China on track and also provide laws for reference for supervision of market in this industry.

Strengthen Technical Guarantee of the Security of China's Mobile E-Commerce

One of the main factors restricting the development of e-commerce is the security issue, so is for mobile e-commerce. If there is no powerful and safe technical support, the development of mobile e-commerce will only remain on the paper.

Perfect Mobile Payment System

A secure payment system cannot only win customers' trust, but also bring huge profits to e-commerce enterprises, so is mobile e-commerce. A perfect mobile payment system needs the efforts of multiple parties, and in addition to a more secure payment platform provided by e-commerce enterprises, mobile operators should also strengthen contacts and cooperation to improve the function and network speed of mobile terminal, remove unreaso nable bound charges and create a humane payment platform while reducing mobile payment costs.

In addition, consumers' weak safety consciousness is also one of the main factors influencing the security of payment.

Perfect Systems Like Online Payment, Security Certification and Offline Distribution and Relevant Laws about E-Commerce, Strengthen Market Supervision

China has a special environment, and in mobile e-commerce, in addition to the unsolved problems in traditional e-commerce like payment and distribution, due to the specificity of mobile e-commerce, the security of mobile e-commerce appears to be especially important.

The rapid development of e-commerce has brought new challenges to the existing legal system. In order to solve all the new problems brought by the informatization of the society and make the information society maintain in benign and orderly development, it is necessary to include the information society in the standardized and legalized track and use legal means to regulate and adjust the new social relationship. However, the traditional legal system is becoming increasingly unable to meet the demands of information society, so legal systems which are suitable for the informationized society should be formulated so that there are laws to be referred to in the supervision of mobile e-commerce market. 
Integrate Hardware and Software Platform of Mobile Terminals and Diversify Software and Hardware Equipment of Mobile Terminals to Provide Momentum for the Development of E-Commerce

As mobile terminal developers adopt different research techniques, mobile phones and tablet computers have different operation systems and application programs, and it is also hard for mobile e-commerce platform which is based on this to meet the demands of multiple operation systems. Therefore, authorities in this industry should formulate standards for China's mobile e-commerce terminal equipment and strictly request the production process of mobile phones and tablet computers. Meanwhile, they should also increase efforts in R\&D as soon as possible and actively coordinate each mobile terminal producer so as to unify the software and hardware platform.

\section{Conclusions}

With the popularity of $3 \mathrm{G}$ network and the development of smart phones and other mobile intelligent terminals, mobile phones has exceeded other terminals and maintained the major access to the Internet. Mobile e-commerce will enter into the stage of rapid development and is gradually penetrated into people's daily life with its influence gradually increased. Howe ver, there are also a lot of problems to be solved with the rapid development. Therefore, the government and mobile e-commerce participants should work closely to jointly create a humane and comprehensive mobile e-commerce service system with high quality, reasonable structure and rich resources, and form a brand new industry chain to actively promote the development of mobile e-commerce.

\section{Acknowledgment}

This work was supported by Project on professional and characteristical construction of Jiangxi province 2010 (Civil Engineering) and Project on the planning and construction of disciplines in Jiangxi University of Technology (Structure Engineering)

\section{References}

[1] Chen Haiting. Review of Current Researches of China's Mobile E-Commerce and Development Trend [J]. Silicon Valley. 2010(16).

[2] Li Qingyan, Jin Duo, Zhang Wenan, etc. Discussion of the Development Trend of Mobile E-Commerce [J]. Telecommunications Science. 2011(6).

[3] Lan Lan. Development and Application of Mobile E-Commerce [J]. Foreign Economy and Trade of Heilongjiang, 2011(11).

[4] Yu Zhouhong. Discussion of China's E-Commerce and its Development [J]. China's Urban Economy, 2012(3).

[5] Zhang Hui. Research of the Application of China's Mobile E-Commerce Based on 3G Technology [M]. Electronic Technology, 2012(3).

[6] Liang Ying. On the Development of China's Mobile E-Commerce [J]. Modern Marketing (academic version). 2012(12).

[7] Liu Yujun. Problems in China's Mobile E-Commerce and Countermeasures [J]. Intelligent Science. 2012(12).

[8] Ma Dayong. Research of Current Situation of China's Mobile E-Commerce and Countermeasures [J]. Computer and the Internet. 2012(10). 
[9] Chinese Industry Research Network. Analysis and Exploration of Mobile Payment Development Trend in 2013 [EB/OL].

[10] Rolf H.Weber. Internet of Things-New security and privacy challenges[J].Computer Law\&Security Review, 2010, (26):84-93.

[11] Wirtz, Oliver Schilke and Sebastian Ullrich. Strategic Development of Business Models 一Implications of the Web 2.0 for Creating Ualue on themInternet[J].Long Range Planning, 2010(43):272-290. 